\title{
Circumflex Artery AV Groove Continuation Artery
}

National Cancer Institute

\section{Source}

National Cancer Institute. Circumflex Artery AV Groove Continuation Artery. NCI

Thesaurus. Code C102287.

The segment of the left circumflex artery that is distal to the third marginal branch, located in the atrioventricular groove. 